Editor-in-Chief

Victoria Chan-Palay - Singapore, Singapore

\title{
Editorial Board Members
}

Dag Aarsland - Stavanger University Hospital, Stavanger, Norway

Suvarna Alladi - National Institute of Mental Health and Neuro Sciences,

Karnataka, India

Marta Altieri - Policlinico Umberto I Clinica Neurologica, Rome, Italy

Stefanie Auer - Donau-Universität Krems, Bad Ischl, Austria

Clive Ballard - Wolfson Centre for Age-Related Diseases, Exter, UK

B. Lynn Beattie - UBC Hospital, Vancouver, BC, Canada

Jean-Christoph Bier - Université Libre de Bruxelles, Brussels, Belgium

Henry Brodaty - Prince of Wales Hospital, Randwick, NSW, Australia

Richard Camicioli - University of Alberta, Edmonton, AB, Canada

Barbara Caracciolo - Karolinska Institutet, Stockholm, Sweden

Jeffrey L. Cummings - Cleveland Clinic, Las Vegas, NV, USA

Jean-François Dartigues - Université de Bordeaux, Bordeaux, France

Mony J. de Leon - NYU School of Medicine, New York, NY, USA

Rachelle S. Doody - Baylor College of Medicine, Houston, TX, USA

Knut Engedal - Vestfold Health Trust, Tønsberg, Norway

Rosemary Fama - Stanford University School of Medicine, Stanford, CA, USA

Howard Feldman - University of California San Diego, La Jolla, CA, USA

Hans Förstl - Klinikum rechts der Isar, Munich, Germany

Samuel E. Gandy - Mount Sinai School of Medicine, New York, NY, USA

Serge Gauthier - McGill Centre for Studies in Aging, Verdun, QC, Canada

Lars Gustafson - Lund University, Lund, Sweden

Mary N. Haan - University of California, San Francisco, CA, USA

Franz F. Hefti - Avid Radiopharmaceuticals, Inc., Philadelphia, PA, USA

Akira Homma - Center for Dementia Care Research and Training, Tokyo, Japan

Michael Hornberger - University of East Anglia, Norwich, UK

Paul G. Ince - Sheffield University Medical School, Sheffield, UK

Kurt A. Jellinger - Institute of Clinical Neurobiology, Vienna, Austria

Peter Johannsen - Rigshospitalet, Copenhagen, Denmark

(Continued on next page) 


\section{Dementia

\section{Editorial Board Members}

Yogeshwar Kalkonde - Society for Education, Action and Research in

Community Health, Gadchiroli, India

Dan Kaufer - The University of North Carolina, Chapel Hill, NC, USA

Ki Woong Kim - Seoul National University, Bundang, South Korea

John Kwok - Neuroscience Research Australia, Sydney, NSW, Australia

Feng Lin - University of Rochester Medical Center, Rochester, NY, USA

Kiyoshi Maeda - Kobe Gakuin University, Kobe, Japan

Colin L. Masters - The University of Melbourne, Melbourne, VIC, Australia

Bruce L. Miller - University of California, San Francisco, CA, USA

Eneida Mioshi - University of East Anglia, Norwich, UK

Urs P. Mosimann - University Hospital of Old Age Psychiatry,

Münchenbuchsee, Switzerland

Hiroaki Naritomi - Senri Chuo Hospital, Osaka, Japan

Tze-Pin Ng - National University Hospital, Singapore, Singapore

Jean-Marc Orgogozo - CHU Pellegrin, Université de Bordeaux, Bordeaux, France

Marian B. Patterson - Case Western Reserve University, Cleveland, OH, USA

Jordi Pérez-Tur - Institut de Biomedicina de València-CSIC, Valencia, Spain

Donald L. Price - Johns Hopkins University, Baltimore, MD, USA

Ramit Ravona-Springer - Sheba Medical Center, Ramat Gan, Israel

Barry Reisberg - Alzheimer's Disease Center, New York University, New York, NY, USA

Karen Ritchie - French National Institute of Medical Research, Montpellier, France

Gustavo C. Roman - Methodist Neurological Institute, Houston, TX, USA

Ingmar Rosén - Lund University Hospital, Lund, Sweden

Martin N. Rossor - National Hospital for Neurology and Neurosurgery, London, UK

Eric Salmon - Centre Hospitalier Universitaire de Liège, Liège, Belgium

Philip Scheltens - VU University Medical Center, Amsterdam, The Netherlands

Marianne Schultzberg - Karolinska Institutet, Stockholm, Sweden

Nobuto Shibata - Juntendo University School of Medicine, Tokyo, Japan

Melissa Slavin - University of New South Wales, Sydney, NSW, Australia

Janine Stein - University of Leipzig, Leipzig, Germany

Hikka Soininen - Kuopio University Hospital, Kuopio, Finland

Masatoshi Takeda - Aino University, Osaka, Japan

Toshihisa Tanaka - Osaka University, Osaka, Japan

Edmond Teng - University of California UCLA, Los Angeles, CA, USA

Katsuya Urakami - Tottori University, Yonago, Japan

Esther van den Berg - Erasmus MC, Rotterdam, The Netherlands

Frans R.J. Verhey - University Hospital of Maastricht, Maastricht, The Netherlands

Gunhild Waldemar - Rigshospitalet, Copenhagen University Hospital,

Copenhagen, Denmark

Christian Wienbruch - University of Konstanz, Konstanz, Germany

Bengt Winblad - Karolinska University Hospital, Stockholm, Sweden 
No. 1-2

Review Article

1 Cognitive Therapy for Dementia Patients: A Systematic Review

Carrion, C. (Barcelona); Folkvord, F. (Barcelona/Nijmegen/Amsterdam); Anastasiadou, D.; Aymerich, M. (Barcelona)

Original Research Articles

27 A Point Prevalence Study of Delirium in Italian Nursing Homes

Morichi, V.; Fedecostante, M. (Ancona); Morandi, A. (Brescia/Cremona); Di Santo, S.G. (Rome); Mazzone, A. (Milan); Mossello, E. (Florence); Bo, M. (Turin); Bianchetti, A.; Rozzini, R. (Brescia); Zanetti, E. (Brescia/Rome); Musicco, M. (Milan/Siena); Ferrari, A. (Reggio Emilia/Rome); Ferrara, N. (Naples/Telese Terme/Florence); Trabucchi, M. (Brescia/Rome); Cherubini, A. (Ancona); Bellelli, G. (Brescia/Monza/Milan); Italian Study Group on Delirium

42 The Head Turning Sign in Dementia and Mild Cognitive Impairment: Its Relationship to Cognition, Behavior, and Cerebrospinal Fluid Biomarkers

Durães, J.; Tábuas-Pereira, M.; Araújo, R.; Duro, D.; Baldeiras, I.; Santiago, B.; Santana, I. (Coimbra)

50 Parietal Involvement in Constructional Apraxia as Measured Using the Pentagon Copying Task

Van der Stigchel, S. (Utrecht); de Bresser, J. (Leiden/Utrecht); Heinen, R.; Koek, H.L.; Reijmer, Y.D.; Biessels, G.J. (Utrecht); van den Berg, E. (Rotterdam); on behalf of the Utrecht Vascular Cognitive Impairment (VCI) Study Group

60 Effects of Physical Activity in Nursing Home Residents with Dementia: A Randomized Controlled Trial Henskens, M.; Nauta, I.M. (Amsterdam); van Eekeren, M.C.A. (Bergen op Zoom); Scherder, E.J.A. (Amsterdam)

81 Dementia Patients Are More Sedentary and Less Physically Active than Age- and Sex-Matched Cognitively Healthy Older Adults

Hartman, Y.A.W.; Karssemeijer, E.G.A.; van Diepen, L.A.M.; Olde Rikkert, M.G.M. (Nijmegen); Thijssen, D.H.J. (Nijmegen/Liverpool)

90 Midlife Stress in Relation to Late-Life Cerebrospinal Fluid Biomarkers of Alzheimer's Disease: A 25-Year Follow-Up Study

Johansson, L.; Kern, S. (Gothenburg); Zetterberg, H. (Gothenburg/London); Blennow, K.; Börjesson-Hansson, A.; Rosengren, L.; Guo, X.; Skoog, I. (Gothenburg)

100 Do Reports on Personal Preferences of Persons with Dementia Predict Their Responses to Group Activities? Cohen-Mansfield, J. (Tel Avi)

109 Psychometric Validation of the Czech Version of the Quality of Life - Alzheimer's Disease Scale in Patients with Early-Stage Dementia

Kisvetrová, H.; Školoudík, D. (Olomouc); Herzig, R.; Vališ, M.; Jurašková, B. (Hradec Králové); Krulová, P. (Ostrava); Langová, K.; Bermellová, J.

(Olomouc); Yamada, Y. (Kyoto)
No. 3-4

Review Article

154 A Review of Diagnostic Impact of Amyloid Positron Emission Tomography Imaging in Clinical Practice

Kim, Y.; Rosenberg, P.; Oh, E. (Baltimore, MD)

Original Research Articles

119 Psychometric Properties and Factor Analysis of the Engagement and Independence in Dementia Questionnaire (EID-Q)

Stoner, C.R. (London); Orrell, M. (Nottingham); Spector, A. (London)

128 A Dementia Café as a Bridgehead for Community-Inclusive Care: Qualitative Analysis of Observations by On-the-Job Training Participants in a Dementia Café

Takechi, H. (Toyoake); Sugihara, Y.; Matsumoto, H.; Yamada, H. (Kyoto)

140 Late-Life Depression versus Amnestic Mild Cognitive Impairment: Alzheimer's Disease Incidence in 4 Years of Follow-Up Lauriola, M.; Mangiacotti, A.; D’Onofrio, G.; Cascavilla, L.; Paris, F.; Ciccone, F. (San Giovanni Rotondo); Greco, M. (Genova); Paroni, G. Seripa, D.; Greco, A. (San Giovanni Rotondo)

168 Quantitative Measurements of Motor Function in Alzheimer's Disease, Frontotemporal Dementia, and Dementia with Lewy Bodies: A Proof-of-Concept Study

Jeppesen Kragh, F.; Bruun, M.; Budtz-Jørgensen, E.; Hjermind, L.E. (Copenhagen); Schubert, R. (Münster); Reilmann, R. (Münster/Tübingen); Nielsen, J.E.; Hasselbalch, S.G. (Copenhagen)

180 C9orf72 Protein Plasmatic Concentrations Are Similar between C9ORF72 Expansion Carriers and Noncarriers in Frontotemporal Dementia

Fourier, A. (Bron); Formaglio, M. (Lyon/Villeurbanne); Sauvée, M. (Grenoble); Perret-Liaudet, A. (Bron/Villeurbanne); Latour, P.; Bost, M. (Bron); Quadrio, I. (Bron/Villeurbanne)

186 Megestrol Acetate Induces Declarative Memory Changes and Cortisol Suppression in Healthy Volunteers

Mason, B.L.; Ivleva, E.I.; Van Enkevort, E.; Nakamura, A.; Brown, E.S. (Dallas, TX)

193 Diabetes, but Not Hypertension and Obesity, Is Associated with Postoperative Cognitive Dysfunction Lachmann, G.; Feinkohl, I.; Borchers, F. (Berlin); Ottens, T.H.; Nathoe, H.M.; Sauer, A.-M.; Dieleman, J.M. (Utrecht); Radtke, F.M. (Næstved); van Dijk, D. (Utrecht); Spies, C.; Pischon, T. (Berlin)

207 An Informant-Based Simple Questionnaire for Language Assessment in Neurodegenerative Disorders

Lin, C.-M.; Hung, G.-U.; Wei, C.-Y. (Changhua); Tzeng, R.-C. (Tainan); Chiu, P.-Y. (Changhua)

217 The Validity of the Norwegian Version of the Cognitive Function Instrument

Michelet, M.; Engedal, K. (Tønsberg/Oslo); Selbæk, G. (Tønsberg/Oslo/ Ottestad); Lund, A. (Oslo); Bjørkløf, G.H. (Tønsberg); Horndalsveen, P.O. (Ottestad); Bergh, S. (Tønsberg/Ottestad)

\section{KARGER}

E-Mail karger@karger.com www.karger.com
(C) 2018 S. Karger AG, Basel

Access to full text and tables of contents, including tentative ones for forthcoming issues: www.karger.com/dem_issues 
229 Alterations in Intra- and Interregional Intrinsic Brain Connectivity Are Differentially Associated with Memory Performance in Amnestic Mild Cognitive Impairment Kang, D.W.; Lim, H.K.; Joo, S.-H.; Lee, N.R.; Lee, C.-U. (Seoul)

243 Screening for Aphasia in NeuroDegeneration for the Diagnosis of Patients with Primary Progressive Aphasia: Clinical Validity and Psychometric Properties

Battista, P. (Bari/Tricase/Florence); Catricalà, E. (Pavia); Piccininni, M. (Bari/Tricase); Copetti, M. (San Giovanni Rotondo); Esposito, V. (Milan); Polito, C. (Florence); Miozzo, A. (Brescia); Gobbi, E. (Milan/Brescia); Cuoco, S. (Salerno); Boschi, V. (Pavia); Picillo, M. (Salerno); Sorbi, S. (Florence); Barone, P. (Salerno); Iannaccone, S. (Milan); Garrard, P. (London); Logroscino, G. (Bari/Tricase); Cappa, S.F. (Pavia/Brescia)

\section{No. 5-6}

Review Articles

285 A Review: Mealtime Difficulties following Frontotemporal Lobar Degeneration

Lewis, C.; Walterfang, M.; Velakoulis, D. (Melbourne, VIC); Vogel, A.P. (Melbourne, VIC/Tübingen)

322 Systematic Review and Meta-Analysis of Prevalence in Post-Stroke Neurocognitive Disorders in Hospital-Based Studies

Barbay, M.; Diouf, M.; Roussel, M.; Godefroy, O. (Amiens); GRECOGVASC study group

371 Effects of Light Treatment on Sleep, Cognition, Mood, and Behavior in Alzheimer's Disease: A Systematic Review Mitolo, M.; Tonon, C.; La Morgia, C.; Testa, C.; Carelli, V.; Lodi, R. (Bologna)

Original Research Articles

253 Neuropsychological Criteria for Mild Cognitive Impairment in the Framingham Heart Study's Old-Old

Wong, C.G.; Thomas, K.R.; Edmonds, E.C.; Weigand, A.J.; Bangen, K.J.

(San Diego, CA/La Jolla, CA); Eppig, J.S. (San Diego, CA); Jak, A.J.

(San Diego, CA/La Jolla, CA); Devine, S.A. (Framingham, MA/Boston, MA);

Delano-Wood, L. (San Diego, CA/La Jolla, CA); Libon, D.J. (Glassboro, NJ);

Edland, S.D. (La Jolla, CA); Au, R. (Framingham, MA/Boston, MA);

Bondi, M.W. (San Diego, CA/La Jolla, CA)
266 Perceptual Inhibition Associated with Sensory Integration for Balance in Older Adults

Redfern, M.S.; Chambers, A.J.; Sparto, P.J.; Furman, J.M.; Jennings, J.R. (Pittsburgh, PA)

275 EEG and Clinical Factors Associated with Mild Cognitive Impairment in Coronary Artery Disease Patients Tarasova, I.V.; Trubnikova, O.A.; Barbarash, O.L. (Kemerovo)

298 Factors Associated with the Caregivers' Desire to Institutionalize Persons with Dementia: A Cross-Sectional Study

Vandepitte, S. (Ghent); Putman, K. (Brussels); Van Den Noortgate, N. Verhaeghe, S. (Ghent); Mormont, E. (Yvoir/Louvain-la-Neuve); Van Wilder, L.; De Smedt, D.; Annemans, L. (Ghent)

310 The Dépistage Cognitif de Québec: A New Clinician's Tool for Early Recognition of Atypical Dementia

Sellami, L.; Meilleur-Durand, S.; Chouinard, A.-M.; Bergeron, D.; Verret, L.; Poulin, S.; Jean, L.; Fortin, M.-P.; Nadeau, Y.; Molin, P.; Caron, S.; Macoir, J. Hudon, C.; Bouchard, R.W.; Laforce Jr., R. (Québec, QC)

335 Validation of the Czech Montreal Cognitive Assessment for Mild Cognitive Impairment due to Alzheimer Disease and Czech Norms in 1,552 Elderly Persons

Bartos, A. (Klecany/Prague); Fayette, D. (Klecany)

346 Neurofilament Light in Serum and Cerebrospinal Fluid of Hip Fracture Patients with Delirium

Halaas, N.B. (Oslo); Blennow, K. (Mölndal); Idland, A.-V.; Wyller, T.B.; Ræder, J.; Frihagen, F.; Staff, A.C. (Oslo); Zetterberg, H. (Mölndal/London); Watne, L.O. (Oslo)

358 The Effectiveness of a Virtual Reality-Based Tai Chi Exercise on Cognitive and Physical Function in Older Adults with Cognitive Impairment

Hsieh, C.-C.; Lin, P.-S. (Taoyuan); Hsu, W.-C. (Taoyuan/Linkou); Wang, J.-S.; Huang, Y.-C.; Lim, A.-Y.; Hsu, Y.-C. (Taoyuan)

385 Acknowledgement to Reviewers

265 Erratum
S. Karger

Medical and Scientific Publishers

Basel $\cdot$ Freiburg $\cdot$ Hartford $\cdot$ Oxford $•$

Bangkok $\cdot$ Dubai $\cdot$ Kuala Lumpur •

Melbourne $\cdot$ Mexico City $\cdot$ Moscow •

New Delhi $\bullet$ Paris $\cdot$ Shanghai $\cdot$ Tokyo

\begin{abstract}
Disclaimer
The statements, opinions and data contained in this publication are solely those of the individual authors and contributors and not of the publisher and the editor(s). The appearance of advertisements in the journal is not a warranty, endorsement, or approval of the products or services advertised or of their effectiveness, quality or safety. The publisher and the editor(s) disclaim responsibility for any injury to persons or property resulting from any ideas, methods, instructions or products referred to in the content or advertisements.

Drug Dosage

The authors and the publisher have exerted every effort to ensure that drug selection and dosage set forth in this text are in accord with current recommendations and practice at the time of publication. However, in view of ongoing research, changes in government regulations, and the constant flow of information relating to drug therapy and drug reactions, the reader is urged to check the package insert for each drug for any change in indications and dosage and for added warnings and precautions. This is particularly important when the recommended agent is a new and/or infrequently employed drug.
\end{abstract}

All rights reserved.

No part of this publication may be translated into other languages, reproduced or utilized in any form or by any means, electronic or mechanical, including photocopying, recording, microcopying, or by any information storage and retrieval system, without permission in writing from the publisher or in the case of photocopying, direct payment of a specified fee to the Copyright Clearance Center (see "General Information").

(c) Copyright 2018 by S. Karger AG CH-4009 Basel (Switzerland)

Printed on acid-free and non-aging paper (ISO 9706) 